\title{
Observations of field-aligned ionospheric irregularities during quiet and disturbed conditions with EKB radar: first results
}

\author{
Oleg I. Berngardt*, Nina A. Zolotukhina and Alexey V. Oinats
}

\begin{abstract}
This paper presents the first results of statistical analysis of 2-year data series obtained with the first midlatitude decameter coherent radar of Russian segment of SuperDARN network. Based on individual events observed on 13-15 December 2013 and 1-4 January 2014, we also demonstrate the possibility of using the radar data for monitoring of magnetosphere-ionosphere dynamics in quiet and disturbed geomagnetic conditions.
\end{abstract}

Keywords: Midlatitude SuperDARN radar; Dynamics of field-aligned ionospheric irregularities; Substorm-like events

\section{Correspondence/Findings Introduction}

Study of statistical characteristics of the scattered signals with use of Super Dual Auroral Radar Network (SuperDARN) (Chisham et al. 2007) is the subject of many papers, for example, the reviews (Chisham et al. 2007; Milan et al. 1997; Ribeiro et al. 2012; Sotirelis et al. 2005; Wild and Grocott 2008). The basic mode of SuperDARN radar is monitoring of the intensity and speed of the smallscale ionospheric irregularities. These irregularities are elongated with the Earth magnetic field and located at $\mathrm{E}$ - and F-layer heights of the ionosphere. Studying of the dynamics of these irregularities allows us to investigate an ionospheric convection in high-latitude regions (Chisham et al. 2007).

Despite the fairly large number of high- and midlatitude SuperDARN radars (more than 30 at the beginning of 2015), a large longitudinal sector corresponding to the high-latitude regions of the Russian Federation remains virtually unexplored. So it is not possible to take into account in modeling and investigating almost a half of the time zones, corresponding to this area.

Earlier investigations of the statistical characteristics of the scattered signals in this region were conducted at higher frequencies and with less modern equipment. The results of these studies are summarized, e.g., in

*Correspondence: berng@iszf.irk.ru

ISTP SB RAS, 126a, Lermontova Str., 664033 Irkutsk, Russia
Bagaryatskii (1961). The study of small-scale ionospheric irregularities at high latitudes of the Russian Federation in a monitoring mode began in December 2012 when first Russian SuperDARN radar near Yekaterinburg (EKB radar, 56N, 58E) had started operations.

The paper presents the first results of statistical analysis of EKB radar data for the period 2013-2014 years, as well as a detailed analysis of the features of the scattered signal observed on 13-15 December 2013 and 1-4 January 2014 at low and moderate geomagnetic activity. High-latitude regions of the Russian Federation have not previously been studied by SuperDARN radars, and the presented results are the first ones for a sufficiently long period of time.

\section{Radar description}

The EKB radar is a SuperDARN stereoradar (Lester et al. 2004; Milan et al. 1997) operating at the frequencies 8-20 MHz, with $45 \mathrm{~km}$ spatial and 1-2-min temporal resolutions. The average power of the radar is about $600 \mathrm{~W}$. In 2013-2014, the radar operated approximately $95 \%$ of time, which made it possible to collect large measurement statistics at different levels of geomagnetic activity.

The radar antenna is a phased array antenna with software control. Measurements of ionospheric parameters are made over 16 directions (beams), changed sequentially. Figure 1 shows the direction of each radar beam and locations of the ground magnetic stations used in this study.

\section{Springer}

(c) 2015 Berngardt et al. Open Access This article is distributed under the terms of the Creative Commons Attribution 4.0 International License (http://creativecommons.org/licenses/by/4.0/), which permits unrestricted use, distribution, and reproduction in any medium, provided you give appropriate credit to the original author(s) and the source, provide a link to the Creative Commons license, and indicate if changes were made. 


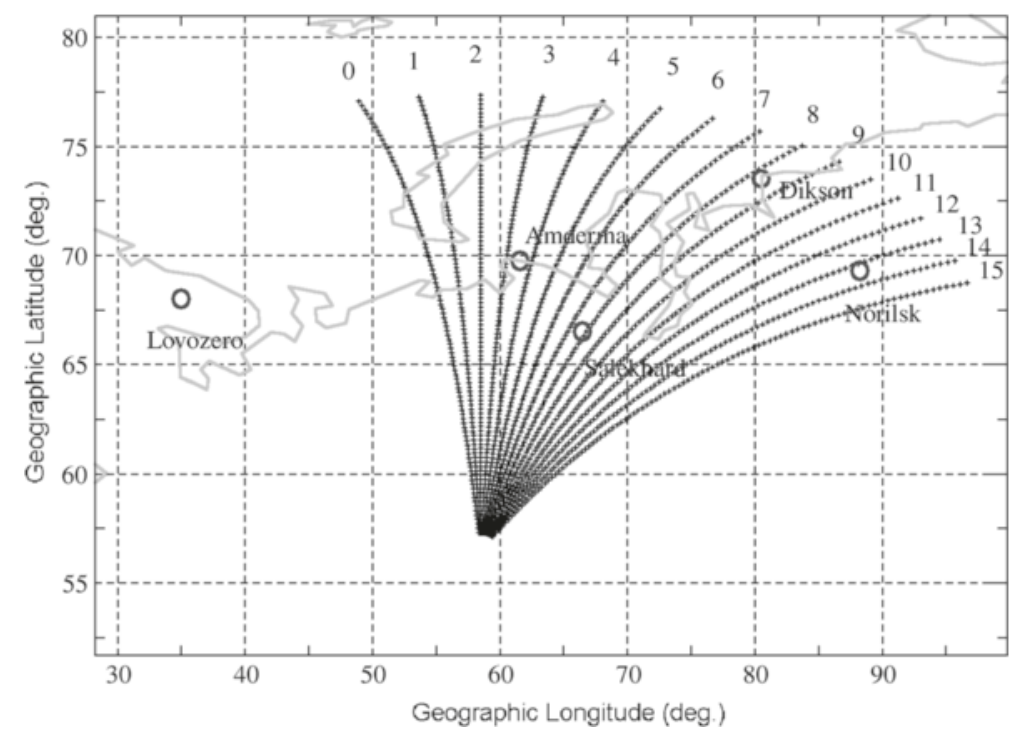

Fig. 1 The geometry of EKB radar observations. The circles mark magnetic stations, the numbers mark radar beams

The principle of the radar operation is sending a complex multi-pulse sounding signal and receiving backscattered signal. The backscattered signal is a mixture of signals scattered by the elongated ionospheric irregularities (ionospheric scatter) and signals, refracted by the ionosphere and scattered from the ground (ground backscatter) (Chisham et al. 2007).

Ionospheric parameters analyzed in this study are estimated with standard SuperDARN FitACF algorithm and are the following:

- $P_{l}$ is the signal-to-noise power ratio for the scattered signal. It is calculated from the shape of the scattered signal correlation function with the standard FitACF technique (Ponomarenko and Waters 2006).

- $V_{D}$ is the Doppler velocity of the irregularities estimated from the phase vs. time lag slope of correlation function.

- $W_{D}$ is the spectral width of the irregularities estimated from correlation function shape.

It is assumed that $V_{D}$ is $E \times B$ convection velocity projection to the radar line-of-sight. In the text below, $V_{D}$ is positive toward the EKB radar and negative in opposite direction. Based on analysis of the velocity and the spectral width, groundscatter signals and signals scattered from the ionosphere were separated.

The EKB radar, unlike many other SuperDARN radars, currently has no additional interferometer phased antenna array. It does not allow us to evaluate elevation angles of received signals and to differ E- and F-layer scattering. In this work, the separation of these signals is made only by checking the delay of the scattered signal. The scattering from the E-layer irregularities comes from heights $90-120 \mathrm{~km}$ and corresponds to the line-of-sight distances from $\approx 500$ to $1200 \mathrm{~km}$. Signals scattered from larger distances and having high absolute velocities $(>40 \mathrm{~m} / \mathrm{s}$ ) are usually associated with scattering at F-layer irregularities.

\section{Statistical characteristics of the scattered signal}

Figure 2 shows the occurrence frequency of ionospheric scatter that was observed by EKB radar in 2013-2014, as a function of the local magnetic time (MLT). The ionospheric scatter signals involved in the statistics were those selected using the standard SuperDARN criteria and whose speed exceeds $40 \mathrm{~m} / \mathrm{s}$ (Blanchard et al. 2009). To eliminate sporadic echoes taken, we analyzed contagious echoes which were detected nearly simultaneously over an area which covered at least 2 neighboring beams $\left(6^{\circ}\right.$ in azimuth) and at least 4 range gates (200 km in distance).

In Fig. 2a, one can see that the most part of the ionospheric scatter is observed at night. It is in a good agreement with the results of observations in this region at other frequencies (Bagaryatskii 1961). Statistically, the number of ionospheric scatter observations correlates well with dynamics of the lower boundary of the convection zone, shown in Fig. $2 \mathrm{~b}$ and calculated for the 2013-2014 years using the model (Weimer 2001). The basic mechanism of this correlation is believed to be the dependence of the magnitude of the irregularities on the external electric field (Foster and Erickson 2000).

According to our observations (Fig. 2c), the maximum number of ionospheric scatter corresponds to corrected geomagnetic latitude $\phi_{s}^{\prime}=63^{\circ}$. It differs significantly from the observations with midlatitude Blackstone SuperDARN radar (Ribeiro et al. 2012) (detected at 


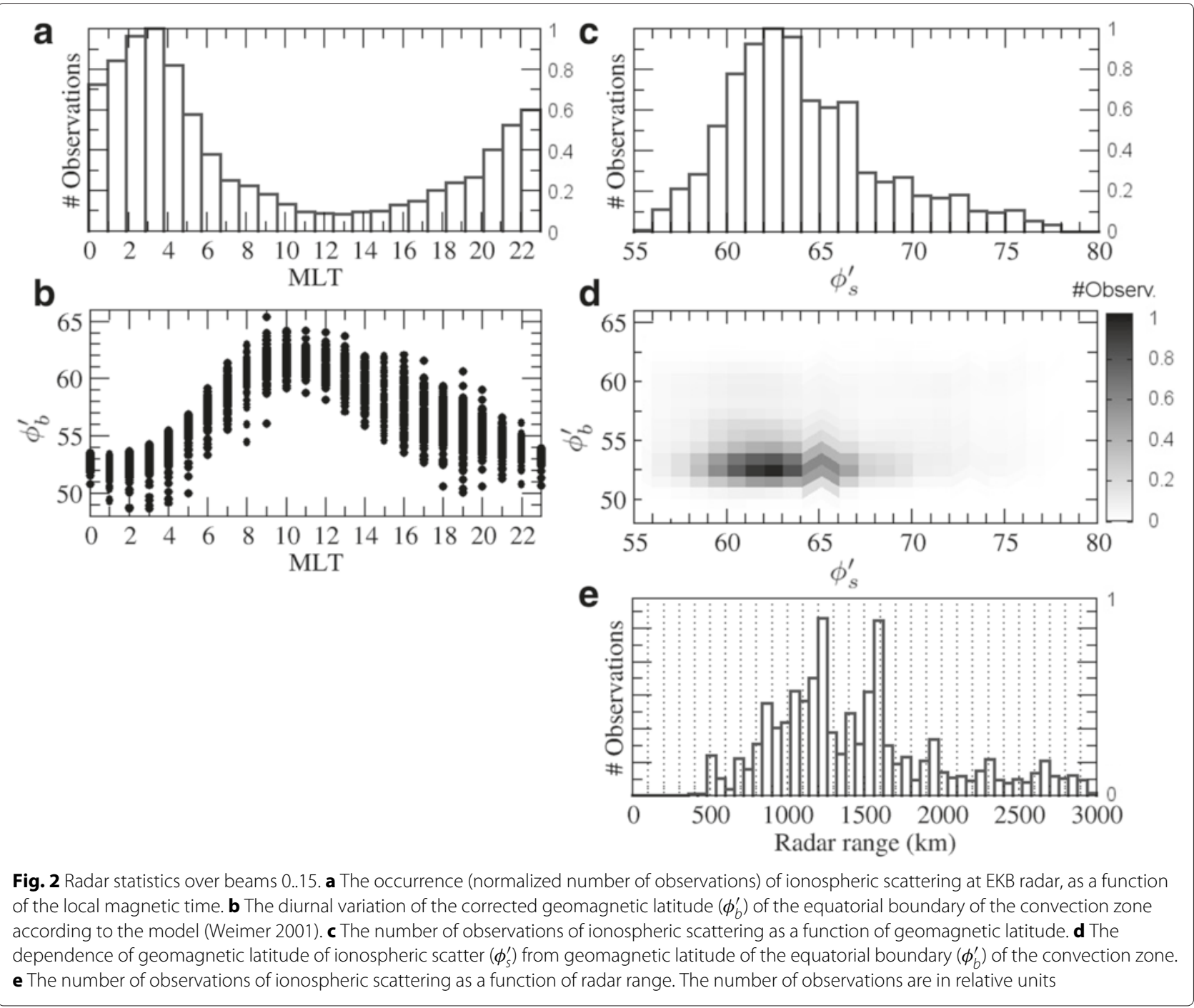

$\left.\phi_{s}^{\prime}=54^{\circ}\right)$. Geomagnetically, the Blackstone radar is located $5^{\circ}-6^{\circ}$ equatorward from the Yekaterinburg radar. Therefore, we can assume that the geomagnetic latitude of the midlatitude radar accounts for only a part of the difference in the location of the echo occurrence maximum. The remaining difference of about $3^{\circ}-4^{\circ}$ can be attributed to a combination of longitudinal asymmetry of the scattering zone and ionospheric refraction.

As it can be seen from Fig. 2a, $d$ that, inspite of statistical correlation between the number of ionospheric scatter observations and the latitude of equatorward boundary of the convection zone, there is no clear correlation between locations of the ionospheric scatter and the lower boundary of the convection zone (Fig. 2d). As one can see in Fig. 2e, the most frequent scatter is observed with EKB radar at $\phi_{s}^{\prime}=\left(58^{\circ} . .68^{\circ}\right)$ (Fig. $2 \mathrm{c}$ ), when lower boundary of the convection zone is located at $\phi_{b}^{\prime}<57^{\circ}$ (Fig. 2d).

The analysis of Fig. 2e shows that the maximum appearance of the ionospheric scattering corresponds to the distance $\approx 1200 \mathrm{~km}$ from the radar (correspond to scattering from E-layer and F-layer irregularities) and distance $\approx 1600 \mathrm{~km}$ from the radar (correspond to scattering from F-layer irregularities only).

\section{Overview of 13-15 December and 1-4 January events}

We will demonstrate a possibility of using of EKB radar data for the study of magnetospheric-ionospheric processes with the examples of the scattered signals received on 13-15 December 2013 and 1-4 January 2014. According to information available at http://www.solen.info/ solar/old_reports/, in those days, the Earth's magnetosphere was under the influence of high-speed streams from coronal holes (CHs). On December, it was CH597; on January, $\mathrm{CH} 598$. Both streams were characterized by high variability of solar wind and interplanetary magnetic field (IMF). Each of them and their associated co-rotating interaction regions (CIRs) caused a series of geomagnetic disturbances, whose effects in geomagnetic indices are 
shown in Fig. 3a, b. High variability of solar wind ram pressure (Psw) and By, Bz components of IMF, observed aboard ACE spacecraft is demonstrated in Fig. 4.

The main features of 13-15 December disturbances were four increases in $\mathrm{Kp}$ index up to $\mathrm{Kp}=2,4,4$, and 3-. The second and third of them were accompanied by the ring current and auroral electrojet amplifications manifested themselves as a decreases in SYM-H and increases in $\mathrm{AE}$ indices, respectively; the first and fourth, with intensifications of magnetopause currents (increases in SYM-H index) caused by increases in Psw. The series of disturbances started simultaneously with the arrival of outer (relative to the Sun) boundary of CIR which, because of a sharp increase in Psw, triggered a positive sudden impulse (SI) with $\Delta \mathrm{SYM}-\mathrm{H}=17 \mathrm{nT}$ at 1323-1329 UT on 13 December. Unlike 13-15 December events, a series of 1-4 January geomagnetic disturbances began $7 \mathrm{~h}$ earlier than CIR arrived. The CIR was observed
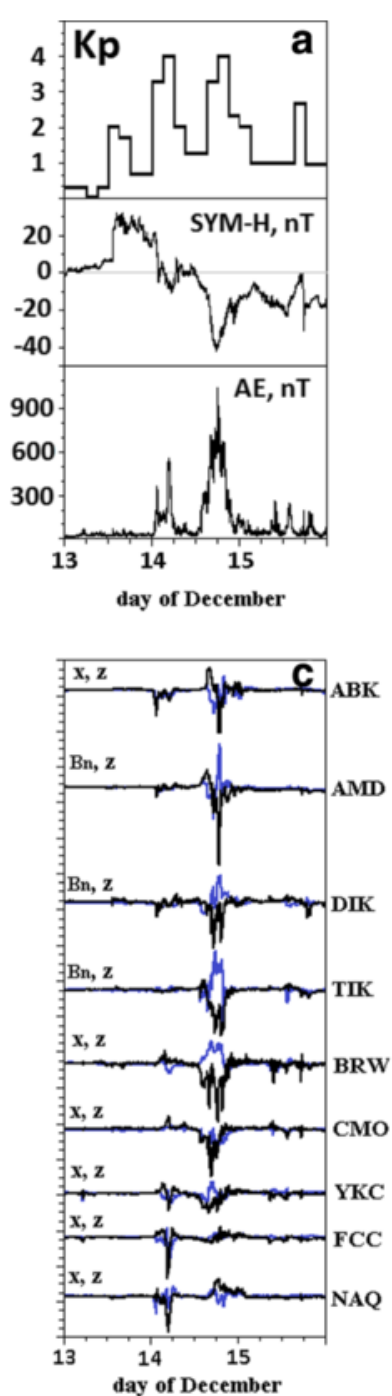
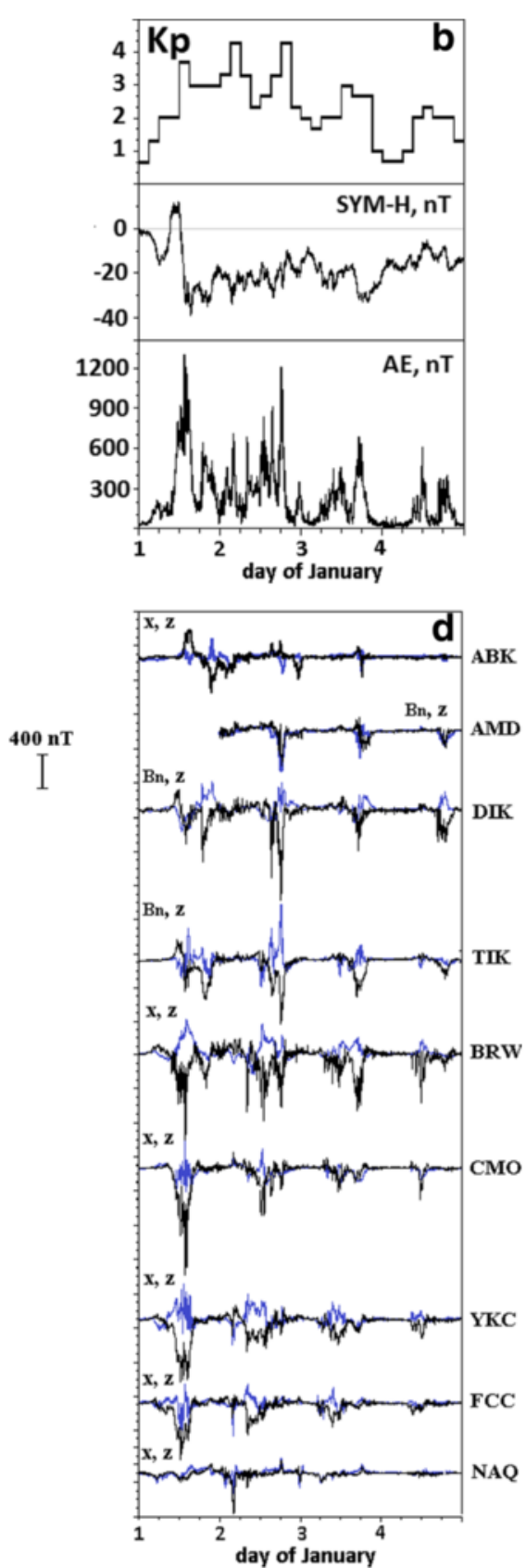

Fig. 3 a, b Variations in Kp, SYM-H, and AE indices; $\mathbf{c}$, $\mathbf{d}$ in geomagnetic $X$ or $\mathrm{Bn}$ and $\mathrm{Z}$ components observed at high-latitude stations. The ABB codes of the stations correspond to those hosted on website http://wdc.kugi.kyoto-u.ac.jp/wdc/obslink.html 


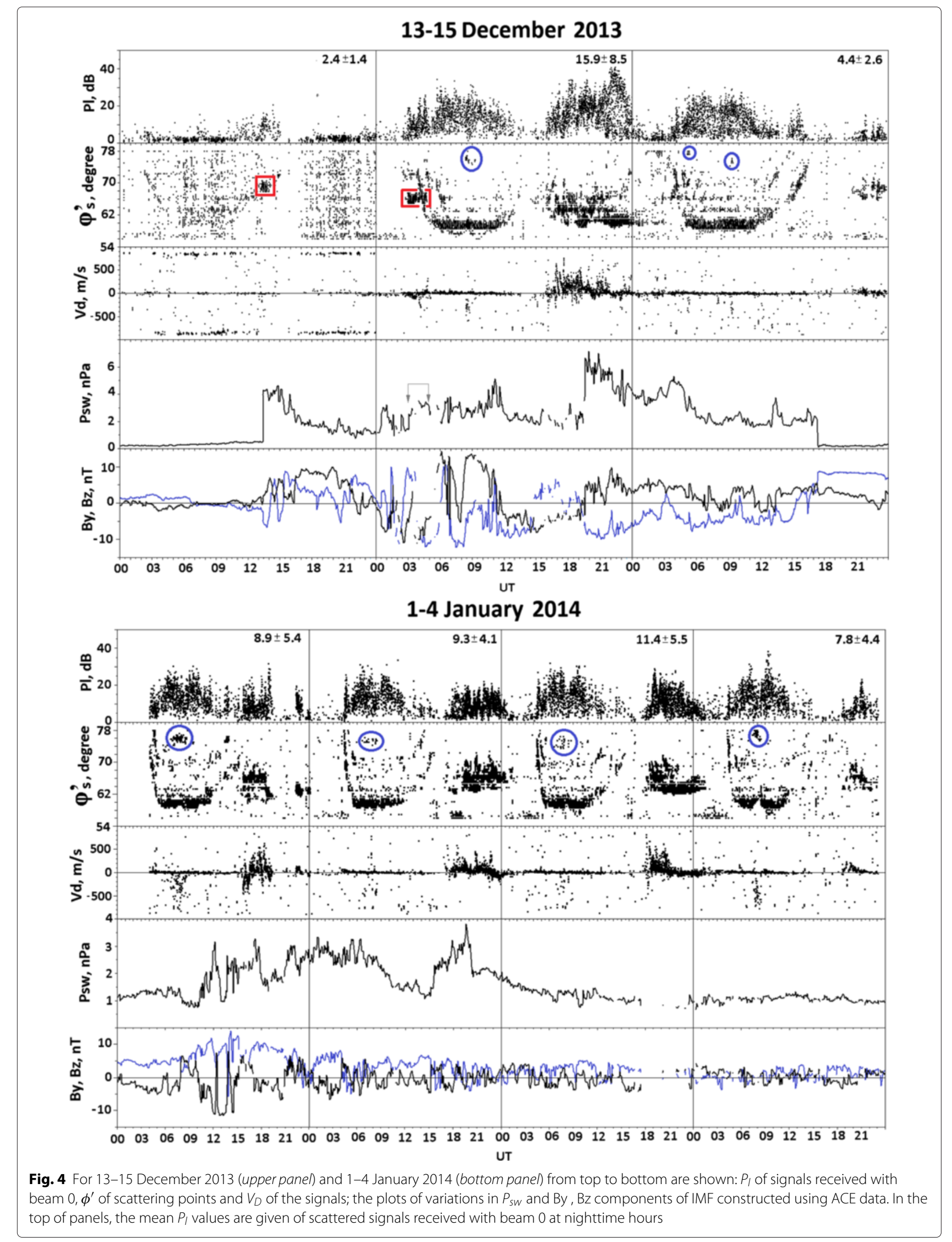


at $\mathrm{ACE}$ at $\approx 10 \mathrm{UT}$ on 1 January and impacted on the magnetosphere 40-60 min later (ftp://ftp.swpc.noaa.gov/ pub/warehouse). In Fig. 3b, one can see that a long-term increase in Kp index began at about $03 \mathrm{UT}$ on 1 January. From this moment till 21 UT on 3 January $K p=2_{-}-4_{+}$. During this time, AE index increased sporadically up to 600-1000 nT, SYM-H varied between -39 and $12 \mathrm{nT}$. There was not well-defined SI associated with the outer boundary of the CIR because of gradual increase in Psw and interplanetary electric field ahead of it.

In Fig. 3c, d, variations in geomagnetic $\mathrm{X}$ (or $\mathrm{Bn}$ ) and $\mathrm{Z}$ components are shown, observed at eight stations which data are used to calculate the $\mathrm{AE}$ index (http://wdc. kugi.kyoto-u.ac.jp/aedir/ae2/AEObs.html). Additionally, we show the graphs of $\mathrm{Bn}$ and $\mathrm{Z}$ disturbances observed at Amderma (AMD, corrected geomagnetic latitude $\phi^{\prime}=65.8^{\circ}$ and longitude $\lambda^{\prime}=136.6^{\circ}$ ) which, as well as Dikson (DIK, $\left.\phi^{\prime}=69.2^{\circ}, \lambda^{\prime}=156.3^{\circ}\right)$, is located in EKB radar field-of-view. Here, Bn and its corresponding $\mathrm{Z}$ are local north and down geomagnetic components which values are hosted on website http://cdaweb.gsfc.nasa.gov; $\mathrm{X}$ and its corresponding $\mathrm{Z}$ components, those hosted on http://www.intermagnet.org/index-eng.php\#.

One can see that the strongest geomagnetic $\mathrm{Bn}$ and $\mathrm{X}$ component disturbances had been observed at 09-15 UT on 1 January in the American sector. In EKB radar fieldof-view, the most intensive $B n$ disturbances were observed at 1830-1900 UT on 14 December at AMD ( $\triangle B n \approx$ $-850 \mathrm{nT})$ and at $1700-1930$ UT on 2 January at DIK $(\Delta B n \approx-1150 \mathrm{nT})$. During the former of them, AMD was located at 2300-2330 MLT; DIK, at 0030-0100 MLT. During the latter one, AMD passed through 2130-2400 MLT; DIK, through 2300-0130 MLT.

\section{Peculiarity of signals scattering in ionospheric F2 layer}

Some of scattered signal features are illustrated in Fig. 4. They are derived from the beam 0 data. We chose this beam because it is oriented in more meridional direction, which results in smaller zonal component of $V_{D}$.
Beam 0 data demonstrate daytime (about 04-14 UT, 08-18 MLT) and nighttime amplifications of signals. Daytime signals are characterized by morning/evening decrease/increase in $\phi_{s}^{\prime}$. These regular U-shaped patterns in ground backscatter signals are associated with daily changes in the electron density and result from refraction of the radiosignal in the regular ionosphere (Frissell et al. 2014; Varrier 2010). They are clearly seen in all graphs except 13 December.

Nighttime data consist of the signals scattered in $\mathrm{F}$ region and are characterized by higher latitudes/ longer distances and those scattered in E region and characterized by lower latitudes/ shorter distances. The mean values of $P_{l}$ in interval 14-24 UT are indicated in the first rows of upper and bottom panels for each day. There is a tendency of increase of the mean $P_{l}$ values with increase in $\mathrm{AE}$ index characterized by linear correlation coefficient 0.85 . This tendency agrees with the well-known relationship between small-scale ionospheric irregularities and auroral electrojet (e.g., Sahr and Fejer 1996).

Of special interest are daytime signals marked by blue ovals in $\phi_{s}^{\prime}(U T)$ graphs of Fig. 4. The time of their observation and mean characteristic are listed in rows 1-7 of Table 1 . These signals were observed in the noontime and came from a relatively small region with dimensions $\Delta \phi^{\prime} \leq 3^{\circ}, \Delta \lambda^{\prime} \leq 2^{\circ}$. They differ from typical daytime ground backscatter (U-shaped area) signals by high latitude of the scatters $\left(\phi_{s}^{\prime}=75^{\circ}-78^{\circ}\right)$ and predominantly northward Doppler velocities which can be as high as $-800 \mathrm{~m} / \mathrm{s}$. Based on published information, we believe that these signals might be scattered in a convection throat region which is characterized by steady antisunward directed flow exceeding $500 \mathrm{~m} / \mathrm{s}$ (e.g., Stern 1996, Shepherd et al. 2003).

Another specific features of the U-shaped areas are also discrete structures, which are clearly seen in the graphs of $\phi_{s}^{\prime}(U T)$ in the morning and evening hours. Each of them corresponds to an increase in $P_{l}$. Two such structures are marked by red rectangles in Fig. 4 . In more detail, we

Table 1 List of daytime reflected signal amplifications according to beam 0 data

\begin{tabular}{llllllll}
\hline No & Date & UT & $P_{l}$ & $V_{D}$ & $\phi_{s}^{\prime}$ & $\lambda_{s}^{\prime}$ & MLT \\
\hline 1 & 14.12 .2013 & $0823-0841$ & $11.8 \pm 5.5$ & $-295 \pm 109$ & $76.2 \pm .6$ & $134-135.6$ & $13.1 \pm .1$ \\
2 & 15.12 .2013 & $0508-0523$ & $5.6 \pm 1.0$ & $-222 \pm 166$ & $77.5 \pm .3$ & $75.1-135.6$ & $133.8-134.5$ \\
3 & 15.12 .2013 & $0910-0925$ & $8.4 \pm 4.8$ & $-278 \pm 131$ & $75.4 \pm .5$ & $13.9 \pm .1$ \\
4 & 01.01 .2014 & $0639-0839$ & $10.1 \pm 3.7$ & $-299 \pm 217$ & $75.8 \pm .6$ & $133.7-135.6$ & $12.2 \pm .5$ \\
5 & 02.01 .2014 & $0652-0826$ & $7.4 \pm 3.4$ & $-258 \pm 228$ & $75.2 \pm .4$ & $133.8-134.4$ & $12.1 \pm .5$ \\
6 & 03.01 .2014 & $0648-0825$ & $8.2 \pm 3.8$ & $-72 \pm 361$ & $75.1 \pm 1.2$ & $133.5-135.6$ & $12.0 \pm .4$ \\
7 & 04.01 .2014 & $0734-0836$ & $9.9 \pm 3.0$ & $-369 \pm 292$ & $77.1 \pm .7$ & $134.2-135.6$ & $12.4 \pm .2$ \\
8 & 13.12 .2013 & $1313-1405$ & $8.0 \pm 3.3$ & $-4 \pm 9$ & $69.4 \pm 1.1$ & $132.2-133.2$ & $18.2 \pm .2$ \\
9 & 14.12 .2013 & $0258-0447$ & $10.8 \pm 4.6$ & $-36 \pm 69$ & $67.6 \pm .8$ & $131.8-132.1$ & $08.0 \pm .6$ \\
\hline
\end{tabular}


show these structures in Fig. 5 and tabulate their mean characteristics in rows 8, 9 of Table 1 .

Evening 8 event was observed against the background of moderate planetary and low auroral activity $(\mathrm{Kp}=2$, $\mathrm{AE}=18-69 \mathrm{nT})$. Scattered signals were received by all the beams. Figure $5 \mathrm{a}$ shows that the signals were received from $\phi^{\prime}=67^{\circ}-71^{\circ}, \lambda^{\prime}=130^{\circ}-180^{\circ}$ region which covered full EKB radar field-of-view by longitude. In this case, $V_{D} \approx 0$ for all the beams. This indicates the absence of clear relationship between the event 8 and changes in the magnetospheric convection. The start of 8 event (marked by gray arrow in Fig. 5a) coincided in time with weak decreases in Psw and SYM-H at 1313 UT; its amplification (marked by black arrow), with sharp increase in the solar wind ram pressure which triggered SI at $1323 \mathrm{UT}(\approx$ $18 \mathrm{nT})$. All these facts indicate that amplification of scattered signals during 8 event could be caused by ionization of the atmosphere by precipitating magnetospheric particles flux increased due to decompression and subsequent compression of the magnetosphere as well as due to penetration of energetic solar particles moving in front of CIR (Prolss 1974).

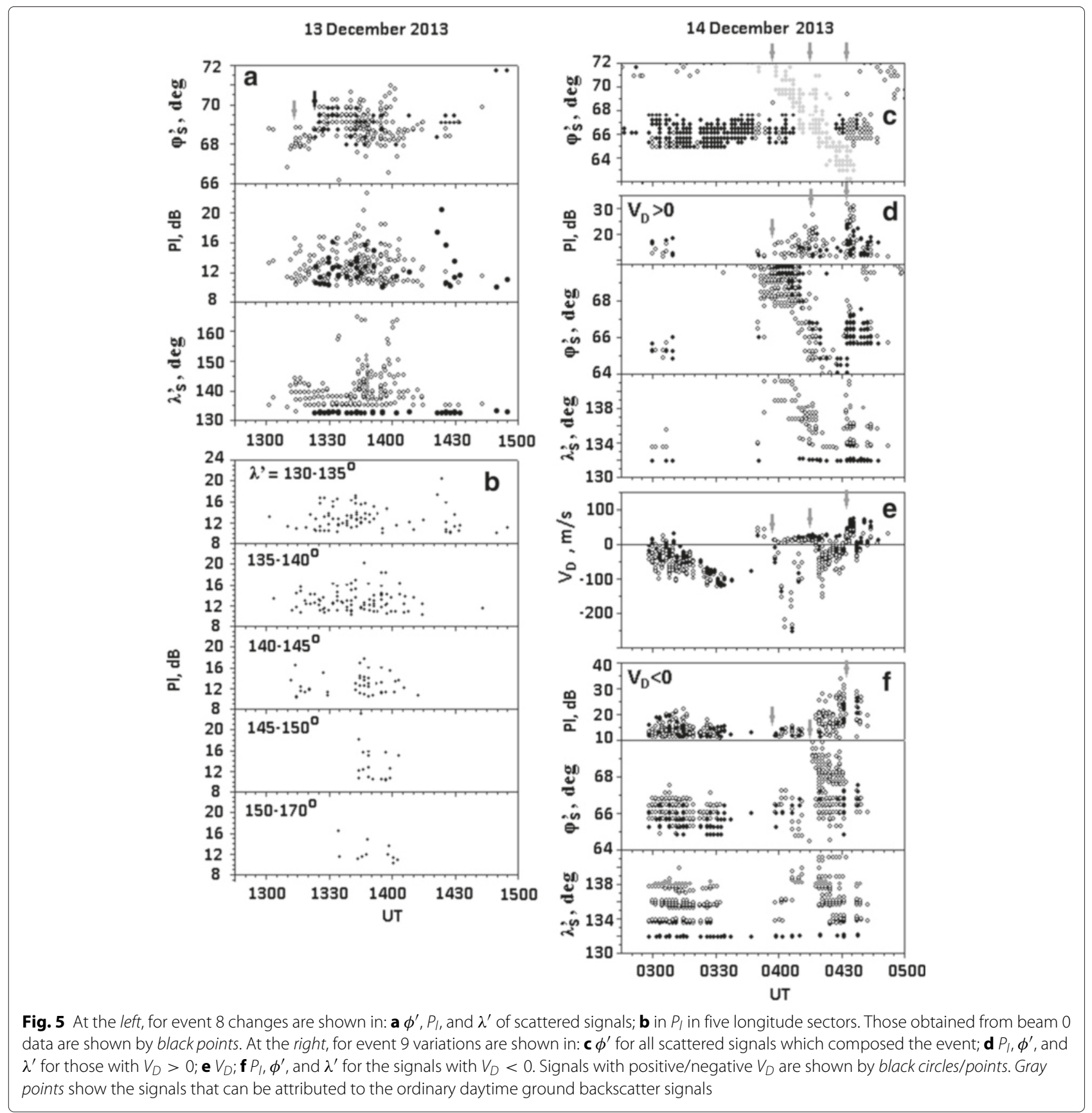


Morning 9 event was observed during a moderate geomagnetic activity $(K p=4, A E \approx 150-550 \mathrm{nT})$. It was visible only in beams $1-4$ and restricted to $\phi^{\prime}=64.5^{\circ}-68^{\circ}$ and $\lambda^{\prime}=132^{\circ}-142^{\circ}$. The start of 9 event coincided in time with increase in Psw from 1.5 to $2.5 \mathrm{nPa}$ at $0300 \mathrm{UT}$ and was accompanied by Psw decrease from 3.5 to $2.5 \mathrm{nPa}$ at $0450 \mathrm{UT}$ (see upper panel in Fig. 4). It points to association between $P_{l}$ enhancement and magnetosphere compression, which triggered atmosphere ionization by precipitating magnetospheric particles observed sometimes as shock aurora (Zhou et al. 2003). The signals appeared between two substorm-like events (SLE) which evolved preliminary in the American sector and manifested themselves as two peaks in $\mathrm{AE}$ index $(\mathrm{AE}=362 / 561 \mathrm{nT}$ at $0131 / 0439 \mathrm{UT}$, Fig. 3a).

Figure $5 \mathrm{c}-\mathrm{f}$ shows the features of signals which composed event 9 in more detail. Based on them, we divided event 9 into two parts. The first one includes the signals observed in $\approx 1-2 \mathrm{~h}$ after the peak of former SLE at 0240-0350 UT. During the first $20 \mathrm{~min}$, weak signals with $P_{l}=3 \pm 1 d B$ (not shown) were received from a narrow latitudinal zone $\phi^{\prime}=66^{\circ}-66.8^{\circ}$. At 0257-0301 UT, the signal "power" sharply increased up to $17 \mathrm{~dB}$ and remained relatively high $\left(P_{l} \approx 11 \pm 4 \mathrm{~dB}\right)$ until $0335 \mathrm{UT}$, their scattering region had widened to $\phi^{\prime}=65^{\circ}-67^{\circ}$. The Doppler velocities were mainly negative and gradually changed from $V_{D} \approx-20 \mathrm{~m} / \mathrm{s}$ at $0257 \mathrm{UT}$ to $V_{D} \approx-110 \mathrm{~m} / \mathrm{s}$ at $0335 \mathrm{UT}$. Taking into account the beam directions, we believe that this is produced by the northeastern drift of ionospheric irregularities resulting from the south-east component of electric field. Such a field arises in the morning Alfven layer due to charge separation of particles supplied into the inner magnetosphere during SLEs. At 0335-0350 UT, the signals were relatively weak $\left(P_{l}=7 \pm 2 \mathrm{~dB}\right)$ and are not shown in Fig. 5. At 0405-0420 UT, the signals with $V_{D}=-20-260 \mathrm{~m} / \mathrm{s}$ were received from $\phi^{\prime} \approx 66^{\circ}-67^{\circ}$. They overlapped with ordinary daytime U-shaped ground backscatter areas.

The further well-defined changes in signal characteristics were associated with the latter SLE which was the most powerful at FCC $\left(58.8^{\circ} \mathrm{N}, 265.9^{\circ} \mathrm{E}\right)$ and NAQ $\left(61.2^{\circ} \mathrm{N}, 314.2^{\circ} \mathrm{E}\right)$, that is at least $95^{\circ}$ to the west and $165^{\circ}$ to the east of radar field-of-view. In Fig. $5 \mathrm{c}-\mathrm{f}$, the start of a sharp decrease in geomagnetic $\mathrm{X}$ component (SLE onset) and its peak (SLE peak) which were observed at FCC at 0420 UT and 0432 UT respectively are marked by gray arrows. In Fig. 3, one can see that no obvious features corresponding this SLE are evident in the AMD and DIK geomagnetic data. Figure 5e demonstrates that negative $V_{D}$ sharply increased up to $-160 \mathrm{~m} / \mathrm{s}$ about 3 min ahead of the SLE onset, then gradually decreased and became positive after the SLE peak. All this points to an association between the event 9 and an enhancement of north-east drift of ionospheric plasma which, as mentioned above, could be caused by Alfven layer polarization field.

Note the presence of two scattering regions at 04200432 UT which are clearly seen in the $\phi_{s}^{\prime}$ graph of Fig. $5 f$. The high-latitude region located at $\phi^{\prime}=67.5^{\circ}--68^{\circ}$ breaks away from the low-latitude one located at $\phi^{\prime}=$ $65.5^{\circ}--67^{\circ}$ at SLE onset. Its progress towards the north was associated with $V_{D} \approx-100-160 \mathrm{~m} / \mathrm{s}$ at the time of the separation.

SLE effects are more visible in nighttime signals. In Fig. 6, they are shown for 14 December. Figure 6a, b shows that the bay-like negative disturbances of geomagnetic $\mathrm{Bn}$ component at DIK and AMD coincide in time with negative bays in the riometer data obtained at the same station. It points to association of both phenomena with enhancements of ionospheric ionization caused by incident auroral particles as it is substorm expansion phase case (e.g., Driatskii 1974). It is pertinent to note that these bay-like disturbances were not a classical substorm but represent some of the multiple intensifications of auroral electrojets which occurred at 1330-2140 UT on 14 December (Fig. 3a). The most powerful intensification of westward jet was observed at AMD at 1830-1900 UT (2300-2330 MLT) and was accompanied by positive north-south (X) and bi-polar east-west $(\mathrm{Y})$ geomagnetic disturbances at midlatitude stations NUS, ARS, and BOX. In Fig. 6c, the maxima of midlatitude $\mathrm{X}$ bays as well as maxima and minima of corresponding Y component variations are marked by black arrows. Note the time lags between $\mathrm{X}$ and $\mathrm{Y}$ extremes observed at spaced by longitude stations. The shown midlatitude horizontal components disturbances may be generated by current system similar to substorm current wedge (Kepko et al. 2014) drifting to the west with a speed about $2.5 \mathrm{~km} / \mathrm{s}$.

Further changes of the scattered signal characteristics during 1300-2300 UT on 14 December are shown in Fig. 6d-f. One can see increases in the power and number of scattered signals $\left(N_{s}\right)$ as well as positive Doppler velocity after $1540 \mathrm{UT}$. They coincide in time with the start of a gradual decrease in latitude of scattering region equatorial boundary (Fig. 6f). These changes appeared at about $25 \mathrm{~min}$ after the start of $\mathrm{AE}$ increase near 1515 UT and could be due to a motion of the convection zone toward the equator because of increased magnetospheric convection. The changes in lowest $\phi_{s}^{\prime}$ were more evident in the signals with $P_{l}<15.9 \mathrm{~dB}$ which represent the mean values of $P_{l}$ over the period 1300-2300 UT. The $N_{s}$ rise and $\phi_{s}^{\prime}$ decrease developed against the background of gradual decrease in the geomagnetic $\mathrm{Bn}$ component at AMD which points to amplification of westward jet in this region. The $N_{s}$ and $\phi_{s}^{\prime}$ changes were accompanied by irregular fluctuations in $V_{D}$ which maximal positive/negative deviations decreased/increased 


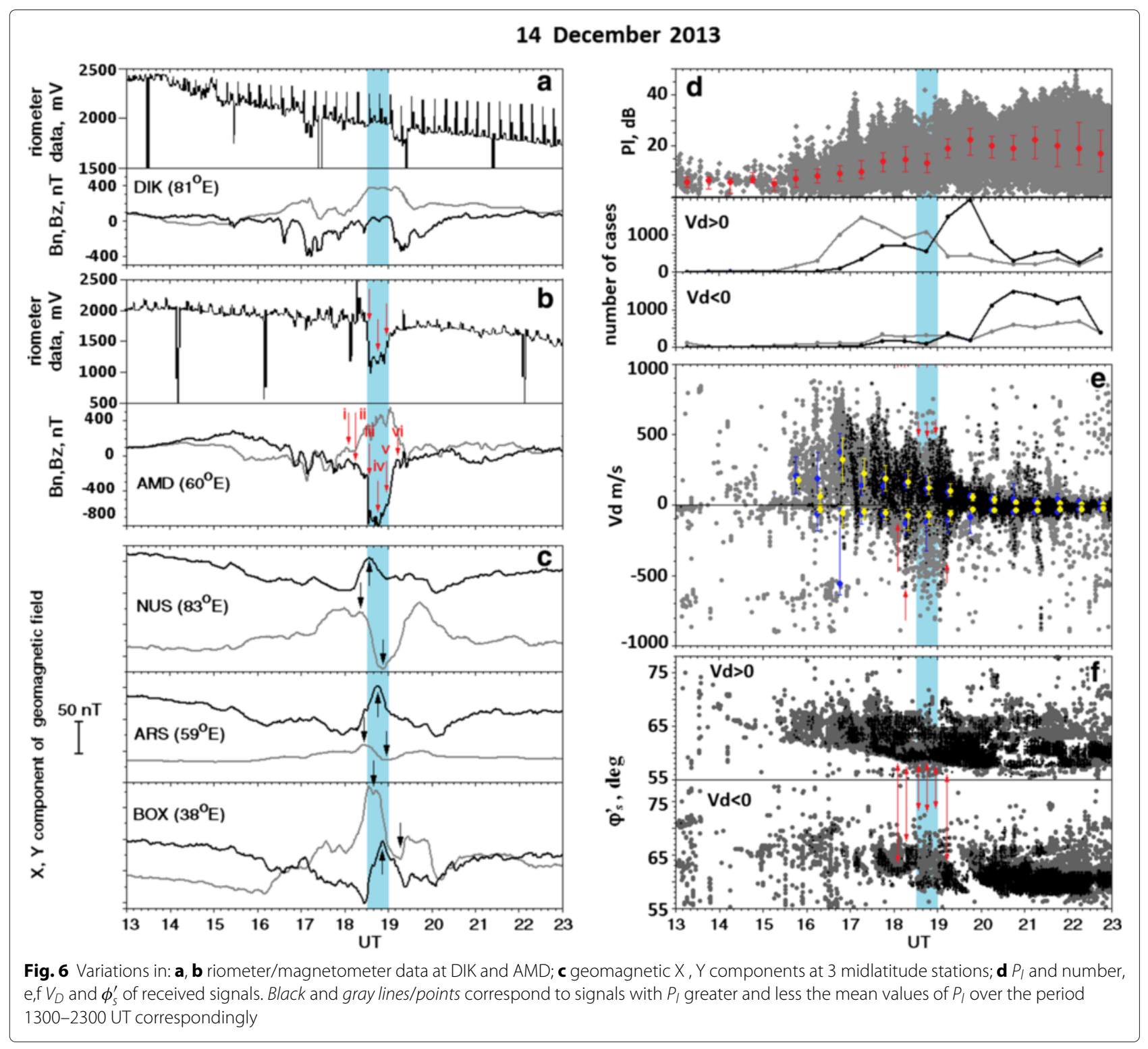

with time. The $V_{D}$ fluctuations were observed up to the sharp decrease in $\mathrm{Bn}$ component at $1830 \mathrm{UT}$ (SLE onset).

In Fig. 6b, red arrows mark the most important moments in SLE dynamics at AMD. They are: (i) - start of gradual Bn decrease; (ii) - transition from $\Delta Z \approx 0$ to $\Delta Z>0$; (iii) - sharp decrease in Bn associated with similar change in riometer data; (iv) - SLE peak; (v) - recovery of $\mathrm{Bn}$ and maximum of $\mathrm{Z}$; (vi) - Bn return to pre-SLE level. In terms of substorm, moments (i, ii) correspond to the growth phase; (iii) - onset; (iv) - peak; (v), recovery phase.

In Fig. 7, we show 5-min maps of the scatter location. The centers of 5-min intervals correspond to moments (i-vi) listed above. The maps demonstrate a spatial dynamics of scattering regions (enhanced ionospheric flows) during the SLE. In five maps, the three separated flow channels are visible: two with $V_{D}>0$ (red symbols) and one with $V_{D}<0$ (blue symbols). Based on results of previous investigations (e.g., Makarevich and Dyson 2007, Zou et al. 2009 and references therein), we suppose that a western high-latitude flow channel of positive $V_{D}$ (FCP1) may be associated with eastward auroral jet , a flow channel of negative $V_{D}$ ( FCN), located to the east of FCP1, is related to westward jet, and a low-latitude flow channel of positive $V_{D}$ (FCP2) is caused by the polarization stream.

Based on the high-latitude geomagnetic disturbances, moments (i) and (ii) differed in latitude of the westward jet center. At (i), the center was located nearby AMD; at (ii), it moved to the south of it $(\Delta B n<0, \Delta Z>0)$. On the map (i), FCP1 is visible at beams $0-8$ and $\phi^{\prime}=62^{\circ}-67^{\circ}$; 


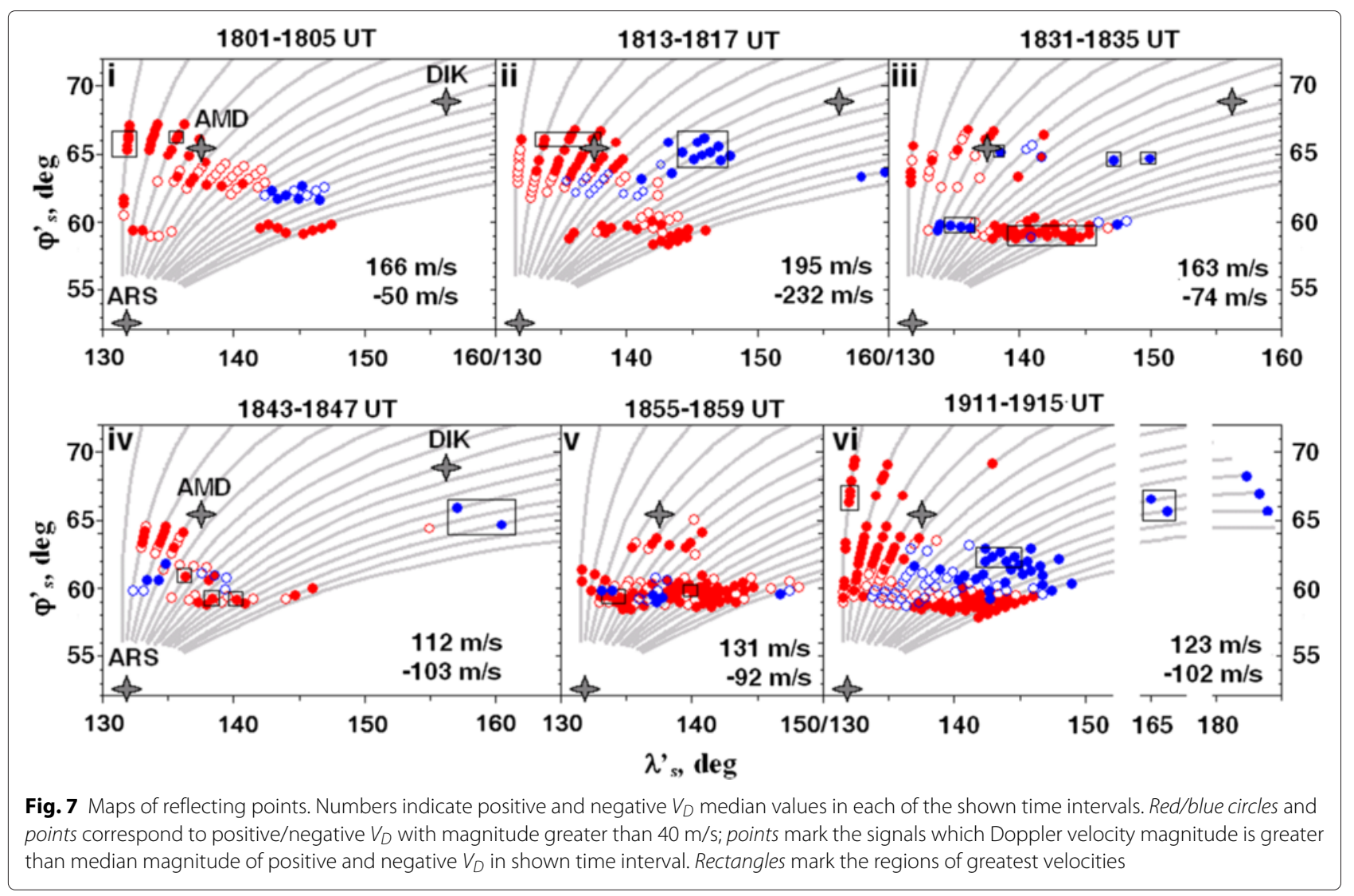

FCN, at beams 9-12 and $\phi^{\prime}=61.5^{\circ}-62.5^{\circ}$; FCP2, at beams $12-15$ and $\phi^{\prime}=59^{\circ}-60^{\circ}$. The Harang discontinuity (Harang reversal) was seen at $\phi^{\prime}=62^{\circ}-63^{\circ}$ between 8 and 9 beams. On the map (ii), the FCP1, FCN, and FCP2 channels were visible at beams $0-6$ and $\phi^{\prime}=$ $62^{\circ}-67^{\circ}$, at beams $3-9$ and $\phi^{\prime}=62^{\circ}-66^{\circ}$, at beams $6-15$ and $\phi^{\prime}=58^{\circ}-61^{\circ}$, respectively. $V_{D}$ values were maximal in magnitude, especially at high-latitude FCP1 and FCN boundaries. The maps show that during SLE growth phase, all three channels shifted to the west; FCN expanded towards the pole and FCP2 expanded towards the pole and equator. Similar changes in locations of magnetosphere-ionosphere currents usually develop during strengthening of magnetospheric convection.

The SLE onset (map (iii)) was followed by the decrease in the number of signals with $P_{l}>15.9 \mathrm{~dB}$ (Fig. 6d). It was associated with the weakening of FCP1 and FCN scattered signals up to their almost complete disappearance in an extended zone equatorward and eastward of AMD. Fragments of FCN are seen only at beams 3-6, 12-15 at $\phi_{s}^{\prime} \approx 59.5^{\circ}$ which was on average roughly $0.5^{\circ}$ to the north from FCP2. It is natural to associate the observed disappearance of the signals with the increase in ionospheric ionization/absorption during SLE expansion phase which was mentioned above.
Transition from SLE onset to SLE maxima (map (iv)) was accompanied by a further displacement of the flow channels and the absorbing zone to earlier hours that match the similar shift of SLE current wedge (Fig. 6c). During SLE recovery phase (map (v)), FCN shifted toward the equator and expanded toward the east; FCN2 expanded toward the pole and west. As a result, it is difficult to separate these flows on the map (v). The FCP1 narrowed up to $\Delta \phi^{\prime} \approx 1^{\circ}$, shifted to the east, and became visible at $\phi^{\prime} \approx 63^{\circ}$, i.e., about $3^{\circ}$ to the south of AMD. After SLE (map (vi)), all three channels were wider by latitude and longitude than those before SLE. The equatorial boundaries of FCP2 and FCN shifted up to $\phi^{\prime} \approx 58^{\circ}$; the western ones, up to $\lambda^{\prime} \approx 133^{\circ}$. Harang reversal also shifted to the west and are visible between beams 5 and 7 at $\phi^{\prime} \approx 59^{\circ}-65^{\circ}$.

Taken together, the results of maps (i-vi) analysis show that the dynamics of high-latitude flow channels during one of the multiple auroral intensifications was similar to that observed during isolated substorms (Zou et al. 2009). The only difference is the existence of the polarization stream (FCP2) before SLE onset that could be associated with enhanced auroral activity before SLE. A similar event was presented in Makarevich and Dyson (2007). 


\section{Features of signals scattered in E-layer of the ionosphere}

In Fig. 8, variations of $P_{l}$ and $V_{D}$ for signals interpreted as E-layer scattering are compared with the magnetic field variations measured near the zone of scattering on 2 January 2014. Figure 8a-d shows the data for 00-24 UT, and Fig. 8e-h shows the data for 20-22 UT. The signals were analyzed in the range $500-1200 \mathrm{~km}$ that corresponds mostly to the scattering from E-layer irregularities. The most intense ionospheric scattering corresponds to the 1200-km range (Fig. 2e).

The figure shows quasi-periodic variations of the scattered signal power and geomagnetic By component with a period of 30-40 min. It should be noted that changes of the signal power $P_{l}$ are not synchronous with the changes of $V_{D}$. This may indicate that the observed effect was not associated with fluctuations in the electric field, or they occur strictly along the radar line-of-sight. Significant fluctuations of By components of magnetic field on the ground can also be interpreted as a changes of the meridional current in the scattering region.
Figure $8 \mathrm{a}-\mathrm{d}$ shows that significant changes of the ionospheric current observed in the period 15-19 UT (Fig. $8 \mathrm{c}-\mathrm{d})$ do not lead to significant changes in the power of the ionospheric scatter (Fig. 8a). This may indicate that the source of the quasiperiodic oscillations observed at 20-22UT (Fig. 8e-h) might not be the changes of the external electric field but rather changes in the E-layer conductivity. Similar statistical results were observed in the UHF radio band: the intensity of ionospheric scatter grows with increase of the background electric field (Foster and Erickson 2000) or E-layer current (Potekhin et al. 1999).

Scattering in the F-layer apparently does not have similar quasiperiodical oscillations.

\section{Conclusion}

We held the first statistical analysis of continuous series of ionospheric scatter data obtained in 2013-2014 by Russian midlatitude decameter coherent EKB radar supplemented by a detailed analysis of individual events,

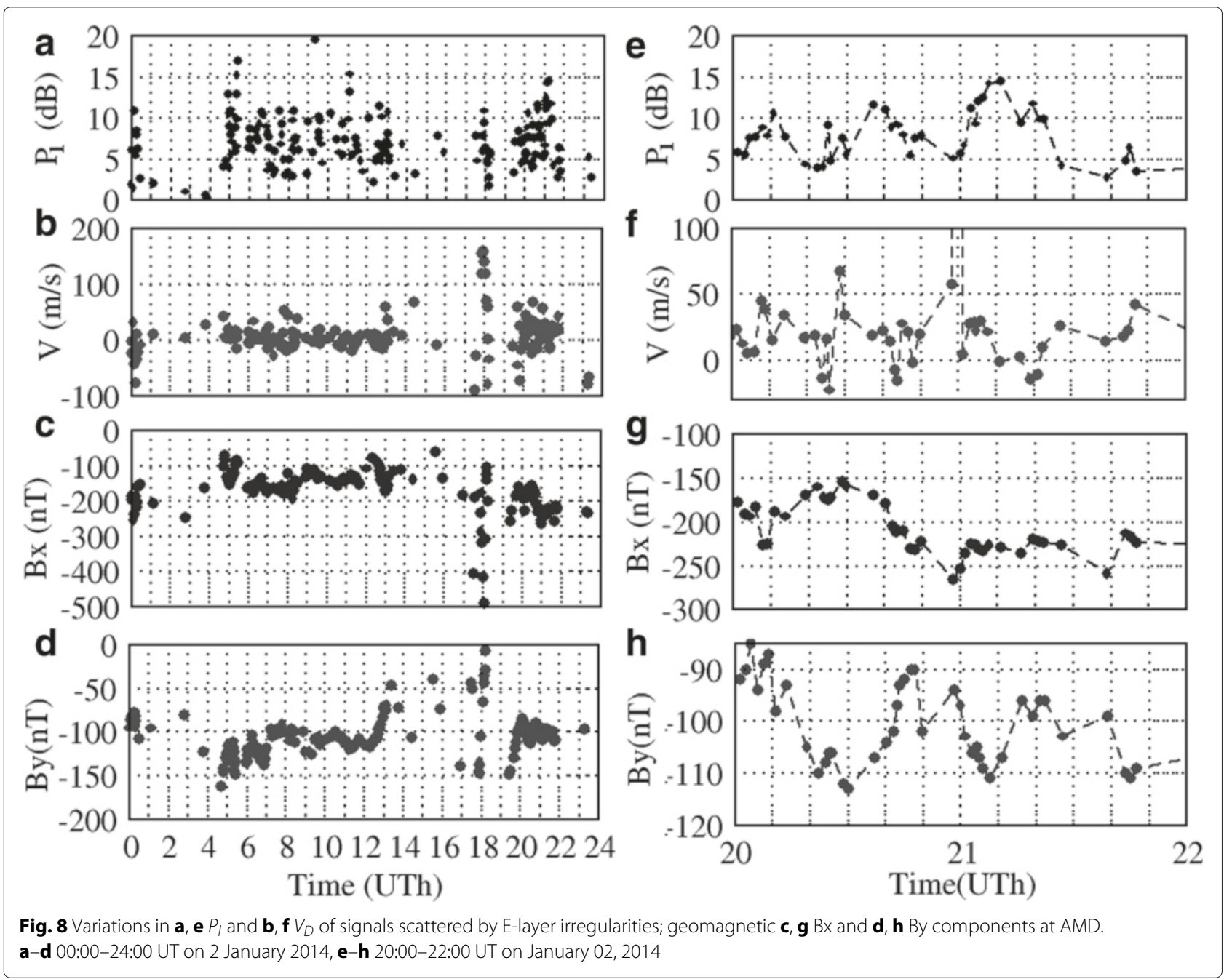


whose features markedly differ from those of regularly observed signals. The statistical analysis showed that:

- Ionospheric scatter occurrence is maximal at 04 MLT and $\phi^{\prime} \approx 63^{\circ}$.

- The diurnal variation of the echo occurrence correlates with the inverted diurnal variation of latitude of convection zone equatorial boundary and latitude of auroral oval (e.g., Feldstein and Starkov 1967).

- The most frequent scatter is observed at $\phi_{s}^{\prime}=\left(58^{\circ}-68^{\circ}\right)$ poleward from the lower boundary of the convection zone, which is located at this time at $\phi_{b}^{\prime}<57^{\circ}$.

Comparative analysis of features of individual scattered signals and geomagnetic activity indicators gave us information about the spatio-temporal dynamics of ionospheric scatterers during expansion-contraction of the magnetosphere and during substorm-like events.

The obtained information allowed us:

- To identify the signals from high-latitude ionosphere scatterers drifting with high speed toward the pole.

The scatterers were clustered in a narrow by latitude and longitude region $\Delta \phi^{\prime} \leq 3^{\circ}, \Delta \lambda^{\prime} \leq 2^{\circ}$ located close to noon meridian and $\phi^{\prime} \approx 76^{\circ}$. Based on the published information, we consider that these scatterers belong to convection throat.

- To show that the evening amplifications of the scattered signal observed on 13 December and characterized by low Doppler velocity was not associated with strengthening of convection field or amplification of auroral currents but with magnetosphere compression-decompression. The amplified signals with $V_{D} \approx 0$ were received from a wide zone which covered the entire EKB radar field-of-view by longitude and could be created by increased flux of incident magnetosphere particles.

- To demonstrate a relationship between intensification of scattered signal in the morning sector on 14 December and two geomagnetic substorm-like disturbances, which evolved in pre-midnight sector, that is, to the west of radar field-of-view.

- To study spatio-temporal dynamics of ionospheric scatterers in region of pre-midnight substorm-like event on 14 December. We show that ionospheric scatterers belonging to westward, eastward, and polarization streams existed before SLE onset. A strengthening of magnetospheric convection during SLE growth phase manifested itself as displacement of westward jet towards the equator. This process was accompanied by the expansion of the scattering region in the same direction as well as to the west, east, and north. Because of the strong absorption, the scatterers were not seen in the region of SLE current wedge which was moving through the radar field-of-view from east to west during SLE expansion phase.

- To reveal a relationship between quasi-periodic variations in signal power and geomagnetic $Y$ component at 20-22 UT on 2 January 2014. In this case, the scattered signals were received from the E-region of ionosphere. Statistical results and the case study of the 2 January 2014 event can be interpreted in terms of the well-known effect observed in the UHF radio band: intensity of the ionospheric irregularities in E-layer grows with the increase in the background electric field or in the current inside the scattering region.

\section{Competing interests}

The authors declare that they have no competing interests.

\section{Authors' contributions}

$\mathrm{OB}$ made the statistical analysis, NZ made the case studies, $\mathrm{AO}$ made the radar data preparation. All authors read and approved the final manuscript.

\section{Acknowledgements}

The study was supported by the Russian Science Foundation (project no. 14-37-00027). We are grateful to AARI for riometer information hosted on http://www.aari.ru/. The results presented in this paper rely on data collected at magnetic observatories. We thank the national institutes that support them and INTERMAGNET for promoting high standards of magnetic observatory practice (www.intermagnet.org). We also thank the managers of the ACE and THEMIS projects for data available on the site http://cdaweb.gsfc.nasa.gov/ istp_public.

Received: 30 April 2015 Accepted: 10 August 2015

Published: 3 September 2015

\section{References}

Bagaryatskii B (1961) Radar reflections from aurorae. Sov Phys Uspekhi 4:70-95 Blanchard GT, Sundeen S, Baker KB (2009) Probabilistic identification of high-frequency radar backscatter from the ground and ionosphere based on spectral characteristics. Radio Science 44(5):RS5012. DOI: 10.1029/2009RS004141

Chisham G, Lester M, Milan SE, Freeman MP, Bristow WA, Grocott A, McWilliams KA, Ruohoniemi JM, Yeoman TK, Dyson PL, Greenwald RA, Kikuchi T, Pinnock M, Rash JPS, Sato N, Sofko GJ, Villain J-P, Walker ADM (2007) A decade of the Super Dual Auroral Radar Network (SuperDARN): scientific achievements, new techniques and future directions. Surv Geophys 28:33-109

Driatskii VM (1974) The nature of anomalous absorption of cosmic radiowaves in the lower ionosphere at high latitudes. Gidrometeoizdat, Leningrad, USSR

Feldstein Yl, Starkov GV (1967) Dynamics of auroral belt and polar geomagnetic disturbances. Planet Space Sci 15(2):209-29

Foster JC, Erickson PJ (2000) Simultaneous observations of E-region coherent backscatter and electric field amplitude at F-region heights with the Millstone Hill UHF Radar. Geophys Res Lett 27:3177-80

Frissell NA, Baker JBH, Ruohoniemi J, Gerrard AJ, Miller ES, Marini JP, West ML, Bristow W (2014) Climatology of medium scale traveling ionospheric disturbances observed by the midlatitude Blackstone SuperDARN radar. J Geophys Res 119(9):7679-7697

Kepko L, McPherron RL, Amm O, Apatenkov S, Baumjohann W, Birn J, Lester M, Nakamura R, Pulkkinen TI, Sergeev V (2014) Substorm current wedge revisited. Space Sci Rev. doi:10.1007/s11214-014-0124-9 
Lester M, Chapman PJ, Cowley SWH, Crooks S, Davies JA, McWillaims K, Milan SE, Parsons M, Payne D, Thomas EC, Thornhill J, Wade NM, Yeoman TK, Barnes RJ (2004) Stereo-CUTLASS-A new capability of the SuperDARN HF radars. Ann Geophys 22:459-73

Makarevich RA, Dyson PL (2007) Dual HF radar study of the subauroral polarization stream. Ann Geophys 25:2579-91

Milan SE, Yeoman TK, Lester M, Thomas EC, Jones TB (1997) Initial backscatter occurrence statistics from the CUTLASS HF radars. Ann Geophys 15:703-18

Ponomarenko PV, Waters CL (2006) Spectral width of SuperDARN echoes: measurement, use and physical interpretation. Ann Geophys 24:115-28

Potekhin AP, Berngardt Ol, Kurkin VI, Shpynev BG, Zherebtsov GA (1999) Observations of abnormally powerful scattering with ISTP IS radar. In: Proc. SPIE 3983, Sixth International Symposium on Atmospheric and Ocean Optics. SPIE, Bellingham, WA, USA. p 328. doi:10.1117/12.370511

Prolss GW (1974) Ionospheric F region storms. In: Handbook of AtmosphericElectrodynamics. CRC Press, Boca Raton. pp 195-248

Ribeiro AJ, Ruohoniemi JM, Baker JBH, Clausen LBN, Greenwald RA, Lester M (2012) A survey of plasma irregularities as seen by the midlatitude Blackstone SuperDARN radar. J Geophys Res 117:A02311

Sahr JD, Fejer BG (1996) Auroral electrojet plasma irregularity theory and experiment: a critical review of present understanding and future directions. J Geophys Res 101:26893-909

Shepherd SG, Ruohoniemi JM, Greenwald RA (2003) Direct measurements of the ionospheric convection variability near the cusp/throat. Geophys Res Lett 30:2109

Sotirelis T, Ruohoniemi JM, Barnes RJ, Newell PT, Greenwald RA, Skura JP, Meng C-I (2005) Comparison of SuperDARN radar boundaries with DMSP particle precipitation boundaries. J Geophys Res 110:A06302

Stern DP (1996) A brief history of magnetospheric physics during the space age. Rev Geophys 34:1-31

Varrier NR (2010) Ray tracing analysis for the mid-latitude SuperDARN HF radar at Blackstone incorporating the IRI-2007 model. Master's thesis, Blacksburg, Virginia

Weimer DR (2001) An improved model of ionospheric electric potentials including substorm perturbations and application to the GEM November 24, 1996 event. J Geophys Res 106:407-16

Wild JA, Grocott A (2008) The influence of magnetospheric substorms on SuperDARN radar backscatter. J Geophys Res 113:A04308

Zhou X-Y, Strangeway RJ, Anderson PC, Sibeck DG, Tsurutani BT, Haerendel G, Frey HU, Arballo JK (2003) Shock aurora: FAST and DMSP observations. J Geophys Res 108:8019

Zou S, Lyons LR, Wang C-P, Boudouridis A, Riohoniemi JM, Anderson PC, Dyson PL, Devlin JC (2009) On the coupling between the Harang reversal evolution and substorm dynamics: A synthesis of SuperDARN, DMSP, and IMAGE observations. J Geophys Res 114:A02311

\section{Submit your manuscript to a SpringerOpen ${ }^{\circ}$ journal and benefit from:}

- Convenient online submission

- Rigorous peer review

- Immediate publication on acceptance

- Open access: articles freely available online

- High visibility within the field

- Retaining the copyright to your article

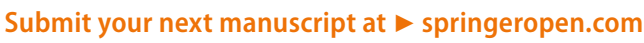

